\title{
Psychological Factors Associated with Habitat Design for Planetary Mission Simulators
}

\author{
Susmita Mohanty \\ Lund Institute of Technology, Department of Architecture and Built Environment, SE-22100 Lund, Sweden \\ Jesper Jørgensen \\ SpaceArch, Vesterbrogade 92, DK-1620 Copenhagen V, Denmark \\ and \\ Maria Nyström, Ph.D. \\ Lund Institute of Technology, Department of Architecture and Built Environment, SE-22100 Lund, Sweden
}

\begin{abstract}
Knowledge and experience of human and technological problems on long-duration missions to Moon and Mars, is at best minimal or worst-case non-existent, as these expeditions are yet to be undertaken. Problems stemming from isolation, inter-group relationships, human response to and interaction with spacecraft interiors in a confined isolated environment have been studied, but in limited ways. On future long-duration planetary missions, the internal environment of the habitat or transit vehicle will be of greater importance than it has been in low earth orbit or short-term missions to the Moon. This paper is in the realm of environmental psychology. In the context of designing space habitats for future long-term interplanetary human space missions, it postulates that it is 'mission critical' to closely integrate 'space architecture, cognitive sciences, human-technology interface design, environmental and personal psychology'. It points out that future planetary simulators are an opportunity to study the relationship between habitat design and crew psychology.

The paper begins with an overview of the origin, scope and limitations of human factors as practiced in the aerospace industry. It presents two case studies that illustrate past endeavors attempting to understand human behavior in the context of long-term isolation and confinement in extreme environments. It highlights behavioral research in Antarctica and its implications for environmental design. It draws attention to a recent study by the European Space Agency that emphasizes the need for psychological research using planetary simulators. It concludes with a discussion that includes (a) the reasons why the relationship between 'habitat design' and 'crew psychology' has not been studied to the extent it should have been, (b) the need for modeling this relationship as a complex 'system' with multidimensional interactions between the various elements in the system, and (c) recommendations for undertaking such studies in the future. The paper concludes with an overview of the various components of the 'system' that could serve as a first step towards modeling and understanding the relationship mentioned above.
\end{abstract}

\section{Introduction}

Knowledge and experience of human and technological problems on long-duration missions to Moon or Mars, especially of future interplanetary missions, is at best minimal or worst-case non-existent, as these expeditions are yet to be undertaken. Problems stemming from isolation, inter-group relationships, human response to and interaction with spacecraft interiors in a confined isolated environment have been documented to a certain extent via crew debriefs, in-situ photos and videos, but the effect of the 'time factor' [mission duration] under these conditions 
is unknown. Experiences from low-orbit space habitats, experiences from polar expeditions and earth bound simulations are a good starting point, but will not suffice if we are to undertake long journeys in the future. On future long-duration missions to Moon and Mars, the internal environment of the habitat or transit vehicle will be of greater importance than it has been in low earth orbit or short-term missions to the Moon. Due to the long travel times or long stays on the planet or both (as in the case of Mars), habitat design must not only be a design for survival of the crew, but a design for every day living.

\section{A. Habitability of Early Spacecraft ${ }^{[1]}$}

Early spacecraft had been designed to be operated, not lived in. The design emphasis was on making them functional, efficient, reliable, and safe. Weight and volume limitations in the Mercury and Gemini "capsules"-the epithet, though despised by crews, was apt-meant that only the bare requirements for protecting and sustaining life could be provided. Michael Collins, pilot on Gemini 10, compared the two-man Gemini craft to the front seats of a Volkswagen. That tiny space was home for Frank Borman and James Lovell for 14 days on Gemini 7. Borman later admitted they had made it on sheer motivation; after accomplishing their prime purpose, the first orbital rendezvous of two spacecraft, and the rest of the mission had been a test of endurance. ${ }^{[2]}$

\section{B. Space Human Factors in Practice: Origin, Scope and Limitations}

In 1967, George Mueller, NASA Associate Administrator for Manned Space Flight at NASA Head Quarters, invited renowned industrial designer Raymond Loewy to serve as a 'Habitability Consultant' for the Saturn-Apollo and Skylab (Skylab was the first American orbiting space station from 1973-1979) projects. Lowey was hired "to help insure the psycho-physiology, safety and comfort of the astronauts" under the "exotic conditions of zero-gravity.".[3] This marked an official recognition by NASA, of the fact that spacecraft architecture and design can significantly influence crew health and behavior. Assisted by a substantial design team, Lowey devised means of promoting both sociability and privacy among astronauts on Skylab missions, argued for the inclusion of a viewing porthole, and suggested ways of handling nutrition, hygiene and elimination in weightlessness. This allowed the astronauts to have a view of earth while in space and grant physiological support. Loewy also installed a triangular table in the Skylab wardroom, so that, as he put it, 'no man from the three-person crew could be at its head.' He felt that in a three-man crew it was vital that no man, however unconsciously, should dominate the others. ${ }^{[4]}$ The Skylab wardroom table is not only demonstrative of the Loewy's concerns for 'habitability', but also of its 'psychological' and 'social' implications for the crew that design brings. Loewy and his team, supported by Muller, put the spotlight on the fact that 'Habitat Design Matters'. Due their efforts, not only did habitability make its way in to the NASA human spaceflight vocabulary, but also psychology, architecture, industrial design, and human factors. Following the Skylab program, human factors engineering became integral to the design process for all human-rated spacecrafts including the Space Shuttle (1981-current) and the International Space Station (1998-current).

Starting in the 1960s, the Soviets too, in their own way, started paying attention to the softer human aspects of living in space once the engineers achieved the goals of safety and survivability. Soviet experience showed that long-term confinement in their small Salyut 6 space station (Soviets launched a series of 7 Salyut stations from 1971-1985, followed by the Mir space station complex from 1986-2001) engendered prolonged episodes of boredom. To alleviate the stress of boredom, Soviet cosmonauts spent many off-duty hours at the station windows to obtain spectacular views of the Earth and aurora borealis. Similarly, Skylab astronauts reported looking out of the window, especially looking back at the Earth, as the most favored off-duty activity. Cosmonauts Berezevoy and Lebedev reported that looking outside for long periods of time replaced watching telecasts of artistic performances and video movies as a form of relaxation. In 1978, Salyut 6 cosmonauts were provided with a videotape player and numerous videotapes of movies. Videotapes depicting natural scenery in the Soviet Union were found to be especially appealing to these cosmonauts. ${ }^{[5]}$

Habitability improvements on subsequent Mir, Space Shuttle and then International Space Station (ISS) are all part of an evolving process resulting from habitability studies, crew debriefs, esthetic experimentation, application, and evaluation in an attempt to provide better living and working conditions for the crew of Earth orbiting spacecraft. 
The Russians (formerly, the Soviets) and the Americans, both have tried to address human factors issues in their own distinct ways. On the American side, the industry term is 'human factors engineering'. It is a broad term that encompasses a slew of human factors issues, including but not limited to, noise, temperature, odors, food, sleep, hygiene, orientation, communication, color, illumination, ergonomics, life-support, man-machine interface, and countermeasures - both physiological and psychological. However, it is important note that each of these issues is addressed with an engineering bias. Therefore, unlike their 'quantitative' counterparts, often the 'qualitative' aspects of human factor issues do not get the attention they deserve. There is a 'gray' zone where quantitative and qualitative factors overlap and this needs to be recognized.

\section{Past Research Overview: Psychological Factors Associated with Habitat Design}

The focus of this research paper - psychological factors associated with habitat design - falls in this 'gray' zone, where both, qualitative and quantitative factors come in to play. While psychological countermeasures such as crew selection, training, in-flight monitoring and support have been an integral part of most of the human missions, especially the latter ones, the other aspects of crew psychology such as the effects of environmental or habitat design, have largely been sidestepped, or at best, been addressed in fairly limited, even disconnected ways. A brief research in to American efforts in the area of 'psychology and habitat design' reveals that intermittent studies have been undertaken by NASA and its contractors from time to time, but most of these research endeavors have lacked continuity and follow-up rigor. These studies have addressed 'selected' (as opposed to a holistic approach) issues of space habitat environmental design as it applies to crew psychology, in direct, and indirect ways. Presented below are two case studies of disciplined enquiries in to the subject. The following two case studies were selected because the authors have access to the Principal Investigators (PIs) for both and could therefore verify the details, credibility and final outcome.

\section{A. Case Study 1}

Reference:

Research Paper titled "Functional Esthetics in Enhancing Well-Being"[5] and direct e-mail communication with the Principal Investigator (PI), Dr. Yvonne Clearwater at NASA Ames Research Center

Research Series Title:

Experiments in Functional Esthetics to Enhance Well-Being in Isolated and Confined Settings.

Study Title:

Habitability Research for ISS Window Inclusion and Design: The Benefits of Simulated Window Views Out to Nature

Year:

From 1984 to 1990, Dr. Yvonne Clearwater led NASA's Habitability Research Program, conducting a wide variety of human factors studies toward design of the International Space Station (ISS), this being one of them

\section{Background:}

- The ISS Habitability Research Team tackled issues of proxemics and physical means to ensure privacy and confidentiality, the use of color as a spatial orientation cue, defining human spatial habitability rules, functional relationship analysis methods to effectively derive placement of key functions and equipment, design elements for crew quarters and wardroom, and window design and placement.

- One of the toughest problems the early ISS design team struggled with was window inclusion, design and location - differentially weighing engineering, economic, and human factors trade-offs. Simply stating that crew members would enjoy looking back to Earth was insufficient when paired with issues involving pressure vessel vulnerabilities and cost concerns. 


\section{Research Objective:}

- Through a series of experiments in settings ranging from a laboratory mock-up of the Space Station wardroom to isolated Antarctic research stations and then in hospital surgical holding areas, Dr. Clearwater and her co-investigators produced hard numbers from the social sciences to clearly demonstrate the psychological and physiological value of opportunities to "look out to familiar nature" via simulated window views - when real windows were unavailable. The team also conducted deep archival research into existing documentation and historical literature.

$\underline{\text { Subjects comprised: }}$

- University students in the laboratory-based pilot studies in a Space Station mock-up at the University of California, Davis.

- Crew members living and working in two Australian Antarctic Research stations for approximately one year.

- Patients awaiting surgical procedures in holding areas in a large hospital.

Experimental Materials:

The 320 photographic high-quality $35 \mathrm{~mm}$ slides used in the study were selected on the basis of their overall international appeal (to avoid cultural bias) - across the categories of landscape scenes with and without structures (from a wide variety of cultures), people engaged in various activities including recreation and sports, animals, human and animal artifacts.

Methods Overview:

- Across the three widely different experimental settings, subjects were asked rate photographs that were mounted as either backlighted transparencies (Wardroom mock-up and Hospital surgical settings) or prints (Antarctic Research Stations) to simulate window views.

- Across all experimental settings, after viewing the photographs for varying periods of time ranging from less than one minute (in pilot laboratory studies), to an average of 30 minutes (Hospital settings), and then up to one year (Antarctic stations), subjects were asked to rate the experimental stimuli on following subjective topics: Preference, Interest, Familiarity, and Enhancement.

- In addition, physiological measures of subjects were taken in the short-term settings consisting of heart rate and blood pressure, as well as pupilary dilation (changes in pupil size) in the pilot studies.

Summary of Findings:

- Picture themes showing photographic landscape views with water consistently scored higher than picture themes showing humans, animals or even landscape paintings. These findings further correlated with higher preference levels for images exhibiting greater apparent depth.

- In particular, results from the long term Antarctic Research Station surveys demonstrated that perception of pictures that depict a variety of Earth-reference cues could serve to combat specific forms of experiential deprivation inherent in confined, austere technical settings such as the International Space Station - by augmenting the diversity of cognitive activity in ways that are familiar and similar to those produced by Earthbound situations.

Follow-up I Application

- The findings of the picture perception studies were translated into space human factors design requirements and submitted to the Manned Systems Panel of the ISS design team. The translated requirements were also submitted for inclusion in JSC 3000 - The Manned Systems Integration Standards.

\section{B. Case Study 2}

Reference: Research Paper titled "Sociokinetic Analysis as a Tool for Optimization of Environmental Design" ${ }^{[6]}$ and direct e-mail communication with the Principal Investigator (PI) Constance Adams 


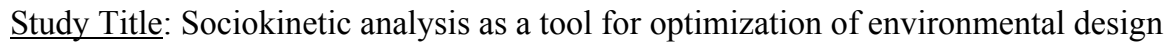

Year: September to December of 1997

Research Objective:

Using sociokinetic analytical methods research the following questions regarding habitat design and crew behavior in the isolation and confinement of a simulated space habitat:

- Does the crew's preference for group versus private areas or other use patterns change over the duration of their confinement?

- All things being equal (i.e., specific site-related activities aside), does the crew prefer more private locations or more public (shared) locations?

- Are there any marked social patterns or behaviors that are anomalous to non-confined groups?

- Are there any marked behaviors that reflect in an unambiguous fashion on known conditions of the crew's environment?

Brief Description:

Sociokinetic analysis is a tool that helps identify patterns in social interaction. In the context of built environments, social interaction is a dynamic constant that expresses itself as a kind of kinesis, or a choreographic pattern, by which the members of a group occupy a given place. The impetus and effectors to any given interaction certainly lie partly in the realm of personal and group psychology, and behavioral psychology shows us many ways of viewing the inherent relationships within any set of group transactions. However, personal or subjective studies alone are insufficient to explain the full set of behaviors that we describe as social interaction, in no small part because the environment in which these interactions happen contains formal elements which (whether by accident or by design) tend to stimulate or to suppress specific behaviors.

In general, these cues seem almost impossibly complex to identify, isolate, or characterize in terms of their behavioral impact. The design of hermetic habitats for long-duration human support in extreme environments (e.g., Arctic, Antarctic, earth orbit, Moon, Mars, etc.), however, renders the need to do so as a matter of the highest importance. Under such circumstances, the habitat itself takes on a uniquely influential role as the primary or sole environment and is thus critical in either supporting or undermining the mental health, productivity, and interactions of its inhabitants. Therefore, the conscious control of environmental cues such as programming, acoustics, and orientation becomes fundamental to the facility's design and, by extension, to the success of the mission.

In order to enable the architect to exercise such control with any kind of precision, tools must be developed that are capable of generating hard requirements based on objective data. One such tool is sociokinetic analysis - that is, the study of the patterns in which a group of individuals within a given environment make use of that environment. This method involves a) the capture of hard data on the use of volumes within a hermetic habitat and b) the application of statistical analysis to their use by a resident group. Strict documentation of the habitat is then weighed against the results in order to force certain environmental design cues to the forefront.

The sociokinetic analytical method was used at NASA's Johnson Space Center (JSC) in 1997. Its first run involved an objective study of the use patterns of JSC's 20 -foot chamber by its all American four-member crew during Phase III of the Lunar Mars Life Support Test Project (LMLSTP) over the 91-day isolation test. Cameras were placed on all three levels of the cylindrical habitat being used for the isolation study. Broadly speaking, the three levels were divided as below:

Level-1: Group Areas + Airlock

Level-2: Equipment to support the basic habitat functions, including bioreactors and gauges.

Level-3: Private Zones I Crew Quarters

At the completion of the test, a total of 512 hours of video was then tracked using statistical analysis software known as SPSS 7.5, and the period of each crewmember's tenure on each floor was quantified in units of seconds. These units were then tracked against time, total duration, and the simultaneous activity of other crew. 


\section{Summary of Findings:}

- Set of locales for socialization: While Level-1 group interactions included any number of crew members up to four; Level-3 group interactions were noted to be of never more than 3 members, and predominantly of only 2 persons at a time.

- Unofficial protocols and boundaries observed: Crew members were never seen entering one another's private quarters. Crew members talking would stand just outside or in the doorway of another member's crew quarters, thus establishing a territorial boundary between the semi-private realm of the corridor/landing and the private realm of the crew quarters. Mutual-boundary interactions also took place as crew members stood in their own doorways and conversed with one another across the landing.

- Percentage of time the crew spent on each floor: It varied less from week to week than had been anticipated. A slight but steady trend was seen toward less use of the Airlock and Level-1 (the group areas) in favor of Level-3 (private zones).

Table 1. Percentage of time crew spent on each floor

\begin{tabular}{llll}
\hline & Week & Week & Week \\
& $\mathbf{3}(\%)$ & $\mathbf{7}(\%)$ & $\mathbf{1 1}(\%)$ \\
\hline Level-3 & 51.6 & 54.9 & 54.8 \\
Level-2 & 4.0 & 2.7 & 3.0 \\
Level-1 & 41.4 & 40.0 & 39.9 \\
Airlock & 3.0 & 2.4 & 2.3 \\
(@level-1) & & & \\
\hline
\end{tabular}

- Temporal Analysis of Usage Patterns: In many instances the use of levels was not surprising. E.g. Level-3 was the area of choice between $24: 00 \mathrm{~h}$ to $08: 00 \mathrm{~h}$ while the crew was sleeping, and Level-1 was most popular around 12:00h (lunchtime) to 20:00h (dinner time).

- Because the exercise equipment was located in the airlock, its use by only a single crew member at a time was extended throughout the waking day with small peaks between 08:00h and 10:00 and between 18:00h and 20:00h as crew members used it for exercise.

- Level-2 usage was, almost exclusively in 20 -second increments steadily throughout the day - it corresponds to the time it took for a person to traverse the Level-2 landing on the stairs while in transit between Level-1 and 3. Occasionally, crew members spent slightly larger blocks of time on Level-2 during equipment maintenance, but the greatest percentage of time stems from the transit function.

- Mirrored Usage Patterns of Level-1 and 3: Use of Level-1 was almost perfectly mirrored by the use of Level-3. When crew-members were not on one, the chances were very high that they were on the other (rather than the Airlock or Level-2).

- This mirroring pattern is unaccompanied by anything but a static, constant baseline in the airlock and Level-2 areas, suggesting that the use or disuse of Levels- 1 and 3 had bearing on one another but no bearing on the occupancy of Level-2 and the Airlock. Thus, 2 of the 4 areas of the habitat (some $35-40 \%$ of the total available area for habitable use) went virtually unused except by necessity, while the other 2 areas became, in essence, the whole of the inhabited volume of the habitat.

- 'Habitable' versus 'Inhabited' volume: This distinction highlights the environments that the crew found unacceptable due to one or more reasons. The pattern of limited use of the airlock could be attributed to environmental factors such as 'cramped volume, cylindrical area with exercise and mechanical equipment, poor layout, unwelcoming setting, uncomfortable outfitting and probably a bit of the 'goldfish bowl' sensibility (part of the habitat exposed to the exterior). Level-2 on the other hand, had more illumination, carpeting, and a cozy corner or two to offer. Only two environmental factors were less than optimal on this level, yet those appear to have had a decisive effect on the usability. Loud acoustic environment due to the noise generated by the equipment, and direct-glare lighting. Although the lighting levels were theoretically 
acceptable by engineering standards, the lack of flexibility in varying the angle and intensity was probably unacceptable.

\section{Follow-up I Application:}

- The study was applied to the two variable schemes the PI designed for the BIO-Plex (Bioregenerative Planetary Life Support System Test Complex) habitat chamber in 1997/98, which were then developed into detailed blueprints by the NASA Johnson Space Center (JSC) Habitability Design Center led by Jan Connolly. Based on those blueprints, the structure and vertical circulation were built into the habitat chamber, but after the subsequent slowdown and reassignment of the BIO-Plex facility from the JSC Advanced Life Support office (ALS) to the Exploration office, it has apparently been lost.

- The BIO-Plex was meant to be space mission simulator combining biological and physicochemical life support technologies to provide all the air and water, and most of the food for a crew of four on a continuous basis. Initially the plan was for the first test to take place in 2000, culminating in a 425-day test starting in 2005. However, in late February 2001, the BIO-Plex Project was put on "stand-by" mode, and later abandoned due to organizational changes at NASA.

- Some basic concepts from the analysis were embedded in the programming of TransHab (inflatable space habitat module being developed by NASA), although less from the front end i.e., the PIs already knew certain maneuvers were a good idea, and incorporated them naturally as good design, but until this study they had no quantitative data to support the requirements. So, this study ended up bolstering requirements for crew performance and productivity, and made the case for user-centered design.

Having reviewed the above behavioral research case studies related to space, the next section takes a brief look at behavioral research in analogous environments such as Antarctica. Unlike their space counterparts, behavioral scientists working with Antarctic crews have been able to achieve greater continuity, better documentation, and therefore more depth in their research. Many of them have been also associated, and quite naturally so, with spacemission related behavioral research.

\section{Behavioral Research in Antarctica: Implications for Environmental Design}

Experience has shown that sustained confinement of workers in remote, isolated, high-risk environments analogous to space produces undesirable symptoms, non-adaptive behaviors, and performance decrements associated with stress. Confined groups in settings such as Antarctic research stations, nuclear submarines, and undersea habitats have demonstrated low morale, heightened anxiety, sleep disturbances, fatigue, reduced productivity, hostility, and interpersonal conflict.

In addition to the above symptoms, research indicates that exposure to Antarctic isolation may produce alterations in consciousness. Increases in hypnotizability bring increased capacity and probability of experiencing a variety of phenomena. Consistent with Smith's findings of widespread daydreaming, these include: deep imaginative involvement and absorption. Changes in susceptibility to hypnosis may also result in:

- Increases or decreases in vigilance performance

- Dissociative or fugue states

- Positive or negative hallucinations, and

- Changes in perception of odors

These phenomena have the potential to facilitate, degrade, or endanger adaptation to Antarctic living, and, by analogy, to life in space. The instances of "bizarre imagery" occurring in space travelers, for example, might be understood through controlled studies of hypnotizability, individual adaptation, and absorption in Antarctica. The findings would, most likely, have direct implications for environmental design and personnel selection for both space and Antarctica. ${ }^{[7]}$ 
The next section draws attention to a recent study by the European Space Agency (ESA) undertaken in 2002 that has put the spotlight on psychological research in light of renewed interest in human missions to Moon and Mars.

\section{REGLISSE: Psychological Research Emphasis in Future Planetary Mission Simulators}

Recognizing the importance of crew psychology, an internal study by the European Space Agency, titled Review of European Ground Laboratories and Infrastructures for Sciences and Support Exploration (REGLISSE) ${ }^{[8]}$ has put 'psychological research' at the core of the research agenda for the future European Planetary Mission Simulator called FIPES (Facility for Integrated Planetary Exploration Simulation). A comprehensive review of possible psychological issues of exploratory spaceflight and the current state of knowledge has been provided in another ESA study called HUMEX that preceded REGLISSE. The HUMEX study outlined a number of recommendations for research and countermeasure development to cover a broad range of topics. Only a few of these topics involve the issues of (hypo)gravity-related effects on human behavior and performance and, thus, require the conditions of real spaceflight to be investigated. Yet, most of the psychological research identified as relevant to prepare for crewed planetary and interplanetary missions addresses issues that do not necessarily require research in actual spaceflight, but research that can also be conducted in high-fidelity simulators here on Earth.

A comprehensive list of such issues can be found in Technical Note (TN) 2 of the HUMEX study ${ }^{[9]}$. The most important of these issues, excerpted from the HUMEX report by the REGLISSE team include:

- Fundamental research concerning mental performance, i.e. effects of confinement and isolation on cognitive performance and perceptual-motor skills,

- Fundamental research concerning maladaptive individual reactions, i.e. impact of prolonged exposure to life-support systems, and confinement and isolation on sleep, circadian rhythm, mood, and mental health,

- Fundamental research concerning interpersonal issues, i.e. impact of confinement and isolation on crew interactions and communication with the outside (including different aspects of crew composition, e.g. effects of differences in personality, motivation, cultural background, gender),

- Applied research and development concerning psychological countermeasures (e.g. crew selection, training, monitoring, and support, as well as selected aspects of habitat design).

\section{Discussion}

The authors of this paper commend the REGLISSE team for putting the spotlight on 'psychological research' for future planetary mission simulators. Often the emphasis of such simulators in the past has largely been on technological aspects (e.g. testing life support systems, air revitalization, etc.). The emphasis needs to be on both technology and psychology. In order to ensure the success of future planetary missions, neither of these two directions can be neglected or favored over the other. They are both critical for the crew and the mission. Imagine a scenario on a mission to Mars, where the technology works, but the crew breaks down either socially, mentally or physically. This could manifest itself in more ways than one. (e.g. fatigue, chronic stress, breakdown of morale, hallucinations, interpersonal conflict, hostile behavior, etc.) If this happens, the crew could end up as a dysfunctional micro-society and no amount of technical prowess can help save the mission.

However, the authors of this paper disagree with the authors of the REGLISSE study on one issue. They believe that although the REGLISSE study has relegated 'Habitat Design' to the category of 'Psychological Countermeasures', it could play a much larger and holistic role in ensuring the well-being of the crew. Habitat Design can be made adaptive, flexible, intelligent and user-responsive to mitigate the negative psychological, social, and physical effects observed in crews subjected to long-term isolation and confinement and enhance the positive ones. 


\section{A. Research Status and Future Directions}

The relationship between habitat design and crew behavior, mental-physical-social health is a research area that has suffered due to the following reasons:

- Ignored, shelved or delayed due to lack of funding, limited research bandwidth, intermittent funding cycles typical of the space sector.

- Camouflaged within the broader context of human factors engineering due to the compulsion for researchers to use terminologies acceptable to the space agencies in order to secure research grants.

- $\quad$ Lacked research continuity and follow-up due to organizational shakeups and project politics.

- $\quad$ Lacked multi-disciplinary, holistic and integrated approach due to lack of collaboration between behavioral sciences, space architecture, and other related fields of expertise.

- Acknowledged in milder rather than bolder terms perhaps due to the taboo associated with astronauts having psychological problems (the taboo has its origins in the paradigm established early on in the history of human spaceflight that astronauts have 'the right stuff', in some sense are superhuman and cannot have problems)

However, in light of future human missions to Moon and Mars, this area of research and expertise needs to developed and nurtured. The success of these human missions lies as much in tackling technological challenges as it does in handling psychological problems.

The research needs to address the following, at the very least:

1. Use Future Planetary Mission Simulators as Research Platforms

United States, Russia and Europe, are planning to build the next generation planetary mission simulators. These simulators should be used as platforms for controlled studies and disciplined enquiry into the subject. It is also important to document the findings from each of the simulations and apply it to the next rotation on an iterative basis to ensure the continuity and evolution of this area of expertise.

\section{Address both Qualitative and Quantitative Concerns}

For example, the usage patterns of Level-2, in Case Study 2 presented above shows that a habitat design issue such as illumination has both a technical and a softer side to it and is an environmental factor that affects crew behavior and comfort. Typically, spacecraft engineers think in terms of the intensity of illuminating source for a given task and the energy required to power it. But there is more to it.

Other technical aspects: Control over the level of illumination, the location and angle of the fixture, the heat and 'white noise' that it produces.

Softer aspects: The type of illumination (fluorescent, incandescent, direct sunlight, earth shine, etc.), the texture of light, the effect of light on colors, the effect on the mood of the inhabitants.

\section{Take a Systems Approach}

The relationship between 'Habitat Design' and 'Crew Psychology and Behavior' needs to be modeled as a system with multidimensional interactions between the various elements in the system. The research needs to address the system as a whole as well as critical components within the global system.

\section{Take a Multi-disciplinary Approach}

The authors believe that this system needs to be defined by a multidisciplinary team comprising among others, Psychologists, Architects, Industrial Designers, Engineers, Physiologists, EVA (Extra-Vehicular Activity), ISRU (In-Situ Resource Utilization) and Life-Support System Experts. As a first step, the section below, attempts to identify some of the major components in this system. 


\section{B. Identifying 'Habitat Design' and 'Crew Psychology' Issues}

As per one of the recommendations in the section above, the authors believe that the relationship between 'Habitat Design' and 'Crew Psychology and Behavior' needs to be modeled as a complex 'system' with multidimensional interactions between the various elements in the system. As a 'first step' in that direction, the authors here attempt to identify issues that can contribute to the creation of a larger 'system' to better understand the 'Psychological Factors Associated with Habitat Design'. The two schematics shown below highlight the issues identified by the authors. These schematics are representative of the plethora of both hard (quantitative, measurable) and soft (qualitative, intangible)) issues that the authors think will play a role in future research.

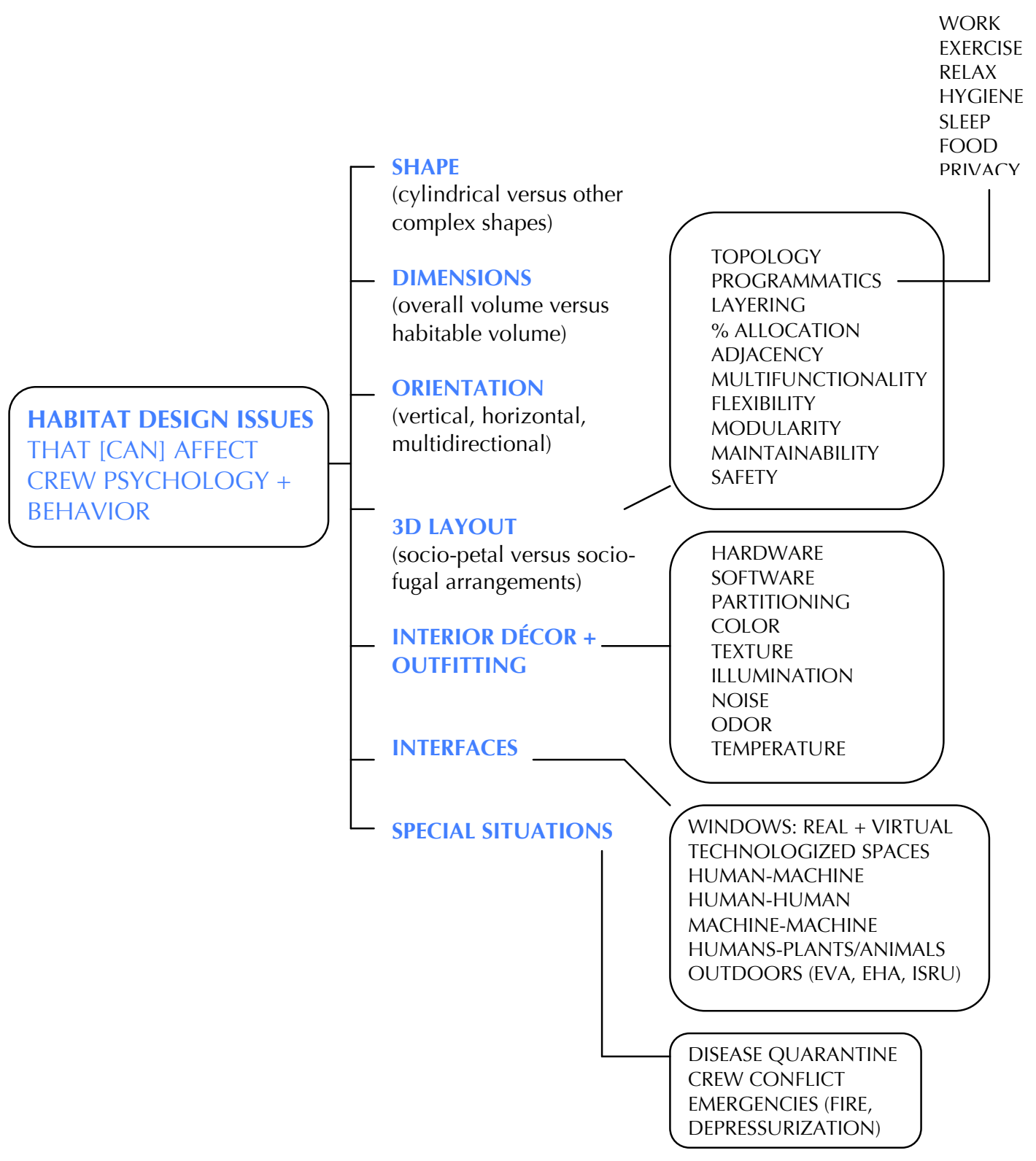

Figure 1. Identifying 'Human Design Issues' that could impact crew psychology and behavior 


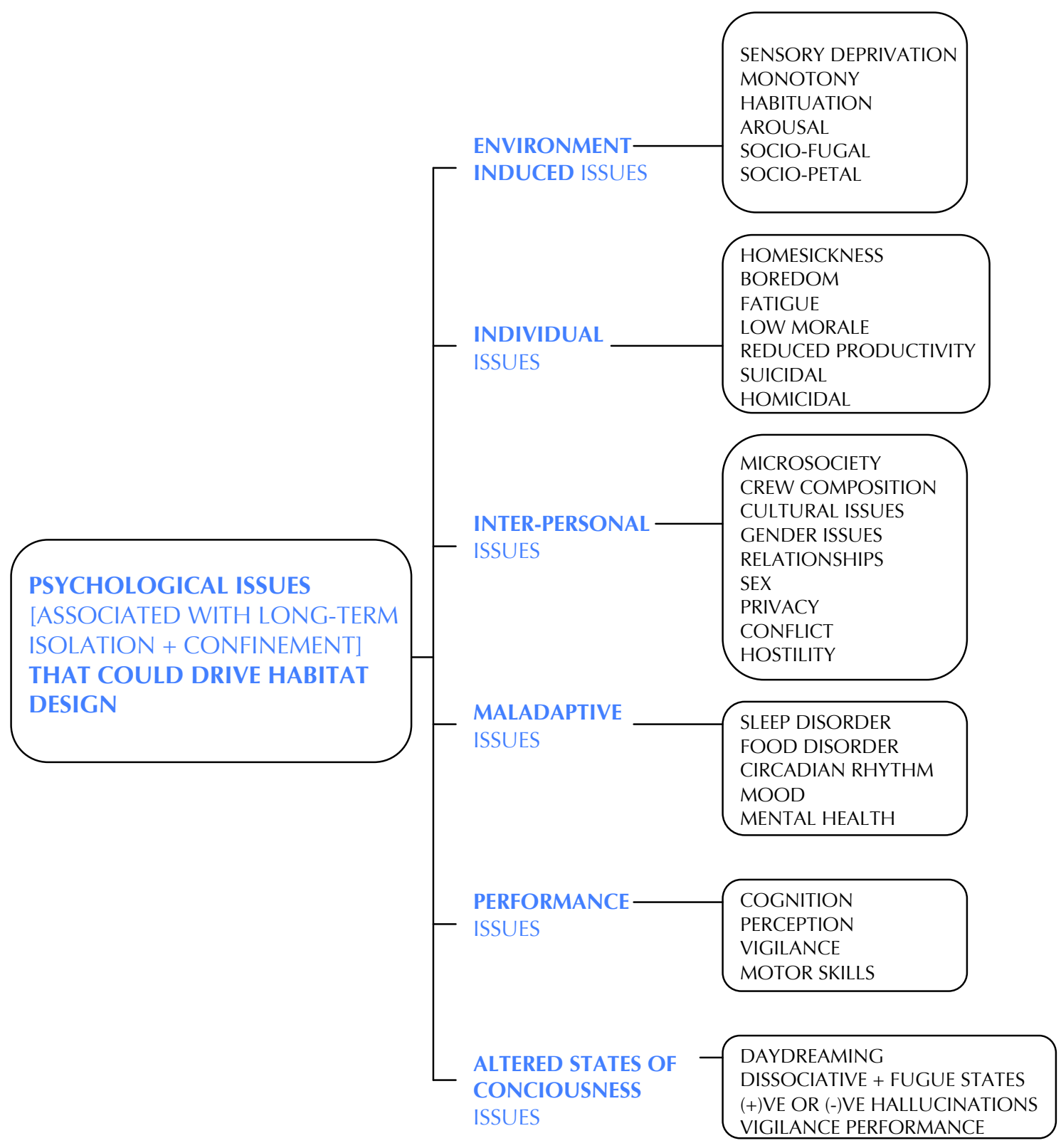

Figure 2. Identifying 'Psychological Issues' that could drive the design of habitats used for long-duration isolation and confinement in extreme environments such as outer space

\section{Recommendations}

The authors hope these schematics can serve as 'tools' for designers of future planetary mission simulators. They could use these as reference 'checklists' to drive the design of the habitat, conduct psychological research and modify the design over time in an iterative fashion using the feedback from crew members participating in longduration simulations. These iterative modifications could occur either between crew changes, or even during the simulation. The designers of future simulators will need to invent tools and methods to accomplish real-time alterations for research purposes. The designers are strongly encouraged to actively involve the simonauts in the design process (i.e. to do the modifications themselves, rather than just experience the space and provide feedback). 
In addition, the design teams need to be multidisciplinary and include, among others, engineers, architects, industrial designers, psychologists, physiologists, and cognitive experts. Another recommendation from the authors is: In order to ensure research credibility, mission durations for these simulations should start with three months and be extended in steps to stretch up to a total of at least a year.

\section{Acknowledgments}

The authors would like to thank Constance Adams of NASA Johnson Space Center and Dr. Yvonne Clearwater of NASA Ames Research Center for their input for the case studies used in this paper.

\section{Abbreviations}

$\begin{array}{ll}\text { ALS } & \text { Advanced Life Support } \\ \text { BIO-Plex } & \text { Bioregenerative Planetary Life Support Systems Test Complex } \\ \text { ESA } & \text { European Space Agency } \\ \text { EVA } & \text { Extra-Vehicular Activity } \\ \text { FIPES } & \text { Facility for Integrated Planetary Exploration Simulation } \\ \text { HUMEX } & \text { Study on the Survivability and Adaptation of Humans to Long-Duration Interplanetary and } \\ & \text { Planetary Environments } \\ \text { ISRU } & \text { In-Situ Resource Utilization } \\ \text { ISS } & \text { International Space Station } \\ \text { JSC } & \text { Johnson Space Center } \\ \text { LMLSTP } & \text { Lunar Mars Life Support Test Project } \\ \text { NASA } & \text { National Aeronautics and Space Administration } \\ \text { PI } & \text { Principal Investigator } \\ \text { REGLISSE } & \text { Review of European Ground Laboratories and Infrastructures for Sciences and Support } \\ & \text { Exploration } \\ \text { TN } & \text { Technical Note }\end{array}$

\section{References}

${ }^{[1]}$ http://history.nasa.gov/SP-4208/ch7.htm [as viewed on 15 August 2006]

${ }^{[2]}$ Borman, F. (1967). Frank Borman interview, 19 Apr. 1967, JSC History Office.

${ }^{[3]}$ http://www.raymondloewy.com/about/bio3.html [as viewed on 15 August 2006]

${ }^{[4]}$ http://www.designboom.com/portrait/loewy transportations.html [as viewed on 15 August 2006]

${ }^{[5]}$ Clearwater, Y. A., \& Coss, R., "Functional Esthetics in Enhancing Well-Being", Antarctica to Outer Space: Life in Isolation and Confinement edited by Harrison, A.A., et al, p. 331-348. Published by Springer-Verlag, New York, 1991. p. 331-348.

${ }^{[6]}$ Adams, C. M., "Sociokinetic Analysis as a Tool for Optimization of Environmental Design", Isolation: NASA Experiments in Closed-Environment Living edited by Lane, H.W., et al, American Astronautical Society, 2002. p.165-175.

${ }^{[7]}$ Barabasz, A. F., “A Review of Antarctic Behavioral Research", Antarctica to Outer Space: Life in Isolation and Confinement edited by Harrison, A.A., et al, Springer-Verlag, New York, 1991. p. 27-28.

[8] "REGLISSE: Review of European Ground Laboratories and Infrastructures for Sciences and Exploration Support", ESA Internal Study, Technical Note 2, Ideal Facility for Psychological Research, ESTEC Ref.: TOS-MCT/2001/3021/In/CL. p. 10-11.

[9] "HUMEX: Study on the Survivability and Adaptation of Humans to Long Duration Interplanetary and Planetary Environments", Technical Note 2, Critical Assessments of the Limiting Factors for Human Health and Performance and Recommendations of Countermeasures. HUMEX TN-002, Issue: Version 1, June 2001. 